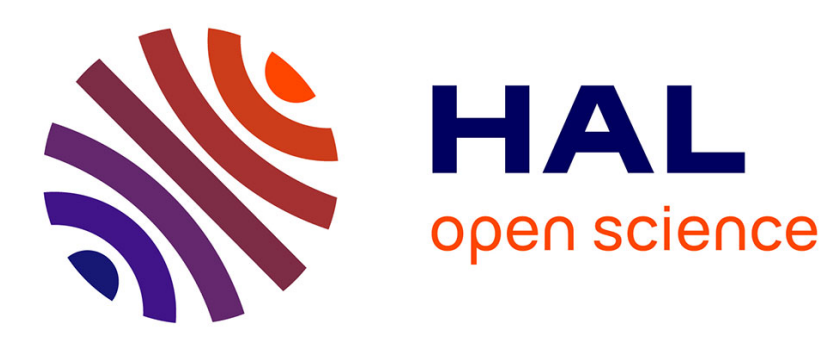

\title{
Crustal accretion at high temperature spreading centres: Rheological control of crustal thickness
}

\author{
Harro Schmeling
}

\section{To cite this version:}

Harro Schmeling. Crustal accretion at high temperature spreading centres: Rheological control of crustal thickness. Physics of the Earth and Planetary Interiors, 2010, 183 (3-4), pp.447. 10.1016/j.pepi.2010.10.004 . hal-00702312

\section{HAL Id: hal-00702312 \\ https://hal.science/hal-00702312}

Submitted on 30 May 2012

HAL is a multi-disciplinary open access archive for the deposit and dissemination of scientific research documents, whether they are published or not. The documents may come from teaching and research institutions in France or abroad, or from public or private research centers.
L'archive ouverte pluridisciplinaire $\mathbf{H A L}$, est destinée au dépôt et à la diffusion de documents scientifiques de niveau recherche, publiés ou non, émanant des établissements d'enseignement et de recherche français ou étrangers, des laboratoires publics ou privés. 


\section{Accepted Manuscript}

Title: Crustal accretion at high temperature spreading centres:

PHYSICS

OF THE EARTH

AND PLANETARY

INTERIORS

Rheological control of crustal thickness

Author: Harro Schmeling

PII: $\quad$ S0031-9201(10)00200-1

DOI: $\quad$ doi:10.1016/j.pepi.2010.10.004

Reference: $\quad$ PEPI 5345

To appear in: $\quad$ Physics of the Earth and Planetary Interiors

Received date: $\quad 7-10-2009$

Revised date: $\quad 27-9-2010$

Accepted date: $\quad 2-10-2010$

Please cite this article as: Schmeling, H., Crustal accretion at high temperature spreading centres: Rheological control of crustal thickness, Physics of the Earth and Planetary Interiors (2010), doi:10.1016/j.pepi.2010.10.004

This is a PDF file of an unedited manuscript that has been accepted for publication. As a service to our customers we are providing this early version of the manuscript. The manuscript will undergo copyediting, typesetting, and review of the resulting proof before it is published in its final form. Please note that during the production process errors may be discovered which could affect the content, and all legal disclaimers that apply to the journal pertain. 


\title{
Crustal accretion at high temperature spreading centres: Rheological
} control of crustal thickness

\author{
Harro Schmeling \\ Department of Geology and Geophysics \\ SOEST,1680 East-West Rd. \\ University of Hawaii, Honolulu, HI 96822 \\ Permanent address: \\ Goethe University, Altenhöferallee 1, 60438 Frankfurt M, Germany
}

Version 3 ( $2^{\text {nd }}$ revision $)$

PEPI in revision 


\begin{abstract}
New determinations of lateral crustal thickness variations at anomalous oceanic spreading centres such as Iceland have shown that the crust may be thinner at the ridge axis above the plume thickening towards the sides (Bjarnason and Schmeling, 2009). To understand this behaviour crustal accretion models have been carried out solving the conservation equations of mass, momentum and energy with melting, melt extraction, and feedback of extracted material as newly formed crust for an extending lithosphere system underlain by a hot mantle plume. The dynamics of rifting are thermally and rheologically controlled by the feedback due to accreted new crust. Four accretional modes with characteristic crustal thickness variations are identified depending on the width of the volcanic emplacement zone, the accretional heating rate, which can be associated with the thickness of the surface layer in which magmatic emplacement takes place, and the spreading rate. Mode 1: Zero crustal thickness at the spreading axis develops for cool accretion and a wide emplacement zone. Mode 2: Strongly or moderately crustal thickening away from the axis develops in case of warm (deep reaching) accretion and wide emplacement zones. Mode 3: Nearly constant crustal thickness develops in case of warm (deep reaching) accretion but narrow emplacement zones. Dynamic topography of mode 3 shows only a weak or no regional minimum at all near the axis. Mode 2 or 3 may be identified with the situation in Iceland. Mode 4: A stagnating central crustal block evolves for cool accretion and narrow emplacement. This mode disappears for increasing spreading rates. No accretional mode with maximum crustal thickness above the plume at the rift axis has been found. The absence of mode 1 accretion (with zero crust at ridge axis) on earth may be an indication that in general crustal accretion is not cold (and shallow). The model is also applied to other hotspot-ridge settings (Azores, Galapagos) and suggests mode 2 to 3 accretion.
\end{abstract}

Keywords: Iceland, oceanic spreading ridge, crust formation, plume-ridge interaction, magmatism 


\section{Introduction}

One important consequence of plume-ridge interaction is an anomalously high melt production rate (e.g. White,1993, Ito et al., 2003; Ruedas et al. 2004). The most prominent example is Iceland, where high melt production rates in combination with low spreading rates lead to crustal thicknesses estimated to range up to $40 \mathrm{~km}$ (Darbyshire et al., 2000; Kaban et al., 2002; Fedorova et al., 2005) (Fig. 1). These studies suggest that the maximum crustal thickness is located in central Iceland in the area of maximum topography. This region might be associated with the location of the plume. Isostatic models by Menke (1999) indicate that a very low density contrast at the Moho is needed to explain the observed Moho - topography correlation. As discussed by Menke (1999) this low density contrast seems too low to be easily explained by high mantle temperatures, retained melt or depletion. Based on similar reasoning, the isostatic models of Kaban et al. (2002) require anomalously high densities of a layer usually associated with the lowermost crust and attribute this layer to a mantle - crust transition zone.

In contrast to the crustal thickness model mentioned above, surface wave inversions by Bjarnason and Schmeling (2009) resulted in a thinner crust $(20-30 \mathrm{~km})$ in central Iceland which thickens away from the rift zone reaching values above $30 \mathrm{~km}$ in Eastern and Western Iceland (Fig. 1). They conjectured that even though the crust is thinner in the central part, hot buoyant asthenosphere and dynamic stresses due to plume flow may be strong enough to produce the maximum topography in central Iceland.

Dynamic models of accretion of Icelandic crust by Schmeling and Marquart (2008) pointed out the possibility of crustal thickening away from the rift zone by a process of lower crust deformation. However, in their study spreading or rifting has been modelled by imposing a kinematic boundary condition to the model surface, which might affect the evolution of the crustal thickness. Furthermore, that assumption prohibited the determination of the dynamic topography, needed to check the above mentioned conjecture of Bjarnason and Schmeling (2009) about the cause of the maximum positive topography above the centre of the plume.

In the present paper the dynamical consistency of the models of Schmeling and Marquart (2008) is improved: The crust formation process is modelled by allowing crustal extension to develop freely due to boundary conditions imposed externally rather than within the rift zone. Furthermore, the experiments are extended to a range of different spreading rates. Most importantly, in contrast to Schmeling and Marquart (2008) accretion parameters are systematically varied to identify new crustal formation modes with different crustal thickness 
variations near the axis. In an application to Iceland it will be investigated under which conditions and parameters a thinned crust beneath the rift axis is found and whether it correlates with high dynamic topography.

\section{Model formulation}

Melting and melt migration within a convecting mantle can be described by the equations of conservation of mass, momentum and energy of a two-phase medium consisting of melt and a deformable matrix in regions above the solidus temperature (McKenzie, 1984; Schmeling, 2000). The equations degenerate to the convection equations of one-phase flow at temperatures below the solidus temperature. The full set of equation is given by Schmeling and Marquart (2008) (SM in the following). Here, only the main aspects and differences to the assumptions by SM are given. The equations are complemented by the rheological equation of state which includes compaction, the permeability - porosity relation with a power-law exponent of 3, and the linearized thermodynamic equation of state including density variations due to temperature, melt fraction and depletion. The heat conductivity is assumed constant and radiogenic heating is assumed zero. Upon melting depletion increases and is advected with the flow. Melting and solidification is modelled using a simplified binary solid solution model with pressure dependent melting function of dry peridotite, see SM for details.

The formation of the crust is modelled in 2D (in the $\mathrm{x}-\mathrm{z}$-coordinate plane) by extraction of all melt exceeding a melt extraction threshold $\varphi_{\text {ex }}$. This threshold is assumed to be $1 \%$ in agreement with the best model of Ruedas et al. (2004) and Schmeling (2006). The total melt extraction rate $\mathrm{q}_{\mathrm{ex}}$ (extracted melt volume per time per unit length in y-direction) is calculated by spatial integration of the local extraction rate. Similar to the downbuilding mechanism of SM, this extruded material is fed back into the model as basaltic crust with a specific accretion temperature $\mathrm{T}_{\mathrm{acc}}$. This is done by imposing an influx boundary condition with a vertical downward depositional velocity $v_{d e p}$ at the top boundary of the model, so that $q_{e x}=-\int_{0}^{L} v_{d e p} d x$, where $L$ is the box length. Laterally this velocity boundary condition is assumed to vary according to a Gaussian shaped emplacement zone $G(x)$ centred at $\mathrm{x}=0$ with a half width $2 d_{a c c}$ (i.e. at $x=d_{a c c}$ the influx velocity is half of the maximum influx velocity)

(Fig. 2). The actual depositional velocity $v_{d e p}$ is given by $v_{d e p}=-G(x) \frac{q_{m}}{L}$. The resulting crustal thickness will be controlled by the rate of the crustal material leaving the accretion 
zone, i.e. the spreading velocity $\mathrm{v}_{\text {spreading }}$ far from the ridge. In a steady state, $q_{m}=h_{c r} v_{\text {spreading }}$, where $h_{c r}$ is the crustal thickness, however, the local or regional thickness variations strongly depend on the dynamics and rheology near the spreading axis.

In the SM models of crustal downbuilding $\mathrm{T}_{\text {acc }}$ was assumed to be $0^{\circ} \mathrm{C}$, thus they represent cold end member models. Here the extruded and accreting material is assumed to retain a fraction of its latent and internal heat during the accretion process. This elevated temperature will have an important effect on the crustal rheology and on the rifting process, which has been neglected in the SM models. What are appropriate values of $\mathrm{T}_{\mathrm{acc}}$ ?

In the appendix of SM a 1D downbuilding deposition model has been developed: Material of $\mathrm{T}_{0}=1200^{\circ} \mathrm{C}$ is continuously fed into a layer of thickness $\Delta \mathrm{h}$ immediately below the earth's surface with an evenly distributed accretion rate. This continuous feedback rate is assumed to represent episodic intrusions of basaltic material (extrusions, dikes, sills, magma chambers) statistically distributed within a layer of thickness $\Delta \mathrm{h}$. As the accretional material source function is assumed constant in that model a vertical downbuilding velocity distribution results which linearly increases from zero at the surface to $v_{\text {dep }}$ at the depth $z=\Delta h$. The resulting $1 \mathrm{D}$ temperature distribution has been determined in SM by solving the appropriate heat equation. These solutions indicate that the temperature increases from zero at the surface to a finite temperature $T_{\text {acc-base }}$ at the base of the intrusion layer at $\mathrm{z}=\Delta \mathrm{h}$. Given a temperature diffusivity of $10^{-6} \mathrm{~m}^{2} \mathrm{~s}^{-1}$, a latent heat of $4 \cdot 10^{5} \mathrm{~J} \mathrm{~kg}^{-1}$, a specific heat of $1300 \mathrm{~J} \mathrm{~K}^{-1}$ $\mathrm{kg}^{-1}$ and an emplacement temperature of $1200{ }^{\circ} \mathrm{C}$, this temperature can be approximated by fitting the empirical formula:

$$
T_{\text {acc-base }}=T_{0} \cdot\left(1-\exp \left(-a v_{d e p} \Delta h-b \sqrt{v_{d e p} \Delta h}\right)\right)
$$

with $\mathrm{a}=3.47 \cdot 10^{5} \mathrm{~s} \mathrm{~m}^{-2}$ and $\mathrm{b}=1.35 \cdot 10^{2} \mathrm{~s}^{1 / 2} \mathrm{~m}^{-1}$. The actual value of $\Delta \mathrm{h}$ is unknown, it represents the crustal region where crust formation takes place by surface extrusions and intrusions (see SM for detailed 2D models of this process). Here only the thermal effect due to a finite $\Delta \mathrm{h}$ of a few km's will be incorporated as a thermal boundary condition at the surface, while the vertically distributed accretion will be simplified by the above mentioned influx condition at the surface.

Within the partially molten region and the region above compaction is accounted for using a modification of the compaction Boussinesq approximation, see SM for details. The solidus and liquidus temperatures are chosen in a way to achieve a normal crustal thickness of $6 \mathrm{~km}$ for passive spreading (i.e. for the case of no plume). The densities are $3500 \mathrm{~kg} / \mathrm{m}^{3}$ for the 
mantle, $3101 \mathrm{~kg} / \mathrm{m}^{3}$ for the melt, $3202.5 \mathrm{~kg} / \mathrm{m}^{3}$ for the depleted material, and (in contrast to SM) $2870 \mathrm{~kg} / \mathrm{m}^{3}$ for the newly formed crust.

The governing equations are solved in a 2-D rectangular region of $200 \mathrm{~km}$ depth and $400 \mathrm{~km}$ width representing one half of a spreading ridge zone, to which an active plume influx is added at the centre. Differently from SM, as thermal initial condition a steady state temperature field of a normal spreading zone with a $\sqrt{t}$-cooling law has been assumed. At $\mathrm{x}$ $=0$ symmetry is imposed. In contrast to $S M$, half spreading velocities of $v_{0}=1,2$, and 4 $\mathrm{cm} / \mathrm{yr}$ are imposed at $\mathrm{x}=400 \mathrm{~km}$. At the top, free slip is assumed and the vertical influx velocity $\mathrm{v}_{\text {dep }}$ within the accretion zone of half width $\mathrm{d}_{\mathrm{acc}}$ is adjusted to match the total amount of extracted melt (see above). In contrast to SM the surface temperature is assumed according to equation (1) using $\mathrm{T}_{0}=1200^{\circ} \mathrm{C}$. At the bottom, free slip and an evenly distributed influx velocity is superimposed with a plume influx velocity with maximum $\mathrm{v}_{\mathrm{p} 0}=10 \mathrm{~cm} / \mathrm{yr}$. The temperature at the bottom is $1391.5^{\circ} \mathrm{C}$, and an excess temperature with maximum $\mathrm{T}_{\mathrm{p} 0}=150$ $\mathrm{K}$ is superimposed. With the adiabatic temperature gradient of the model the background bottom temperature implies a potential surface temperature of $1334^{\circ} \mathrm{C}$. For more details on the boundary conditions, see SM.

For the mantle a temperature- and pressure dependent non-Newtonian rheology with a power law exponent 3.5 has been used based on laboratory measurements of single crystal olivine (Bai et al., 1991). A detailed description of this composite dislocation creep law representing dry olivine is given in Schmeling and Bussod (1996), where also a list of the various parameters used in the models can be found (Table 1 in Schmeling and Bussod, 1996). For simplicity the same rheology is applied to the depleted and undepleted mantle. In contrast to SM for the newly formed crust the rheology of clinopyroxenite with a power law exponent of 2.6 has been assumed (Kirby and Kronenberg, 1987). A depth-dependent plastic Byerlee-type rheology has been superimposed with a frictional coefficient of 0.4 and a cohesion strength of $25 \mathrm{MPa}$.

The equations are solved with the finite difference code FDCON on a 401 x 201 grid for the temperature and melt transport equations and on a 201 x 101 grid for the flow equations (e.g. Schmeling, 2000, 2006).

\section{Results}

Two model series have been carried out for each spreading rate, in which two parameters controlling the crustal accretion have been varied: a) the width of the emplacement zone, $d_{a c c}$, 
b) the accretion temperature, controlled by the accretion layer thickness, $\Delta \mathrm{h}$. Depending on these parameters 4 modes of crustal accretion could be identified, three of which have not previously been found by SM..

\section{Mode 1: Zero crustal thickness at rift axis}

Fig. 3) shows an example of what we call mode 1 crust formation. Assuming a large (half) emplacement width of $50 \mathrm{~km}$ and a cold accretion mode $(\Delta \mathrm{h}=0)$ the emplaced crust (see the streamlines entering the model from the top) and the upper mantle are cooled efficiently. As a result a rheologically strong lithosphere is formed, which rifts by necking within a narrow region at the rift axis (see viscosity field). The lithosphere is mechanically decoupled from the symmetric counterpart on the left hand side of the box. As a result material accreting near the axis is immediately stretched and transported sideways. The mantle wedge reaches almost the surface, and the crustal thickness at the rift axis is almost zero despite the fact that it is underlain by a productive plume. This rheologically controlled stretching zone turns out to be significantly narrower than the prescribed crust accretion zone of $50 \mathrm{~km}$ (half-) width. Based on their kinematic models, Ruedas and Schmeling (2008) inferred that indeed such a combination of stretching zone width and accretion zone width always results in significant crustal thinning at the rift axis. The present dynamical model verifies these findings and emphasized the important role of rheological localization of rifting. Outside the accretion zone $(\mathrm{x}>100 \mathrm{~km})$ a rather constant crustal thickness of about $20 \mathrm{~km}$ is reached, representing the steady state equilibrium between the melt extraction rate $q_{m}$ and the crust production rate $h_{c r} v_{\text {spreading. }}$

\section{Modes 2 and 3: Accreting and spreading crust, thickening towards the sides}

While the previous model represents a cold accretional end member, in a number of model runs the accretion thickness $(\Delta \mathrm{h})$ has been increased by appropriately increasing the temperature of the extracted crustal material as it is fed back into the model from above. Fig. 4) shows models with influx temperatures corresponding to thicknesses $\Delta \mathrm{h}$ up to $6 \mathrm{~km}$. According to equation 1 the temperature of the accreting crust gets hotter with increasing $\Delta \mathrm{h}$. As peak temperatures (associated with the most productive melt generation episode during the model evolution) may reach values between 400 and $800{ }^{\circ} \mathrm{C}$ and long term accretion temperatures are still of the order of 200 to $400{ }^{\circ} \mathrm{C}$, significant crustal or lithospheric 
weakening is observed in these models. As depicted in Fig. 5), the effective crustal viscosity is reduced to $10^{21} \mathrm{~Pa}$ s or below almost all along the full accretion width of $50 \mathrm{~km}$. This allows significant stretching and deformation within this accretion zone and no central necking of the lithosphere takes place as it does in the cold end member model (c.f. Fig. 4) (models with $\Delta \mathrm{h}=0$ or $2 \mathrm{~km}$ show necking, models with $\Delta \mathrm{h}=4$ or $6 \mathrm{~km}$ show distributed stretching). Within the accretion zone the weak crust is still squeezed sideways, which leads to some thickening towards the sides. This mode 2 will be called "strongly thickening crust". As also shown in Fig. 5), the different rheologies of the crust and mantle lead to a stratification of the effective viscosity. The lower crust is characterized by a low viscosity zone.

While the model shown in Fig. 4) shows some thickening towards the sides even for the hottest accretion, this effect is reduced if a narrower emplacement width is chosen. Fig. 6) shows a model comparable to that of Fig. 4), the difference being an emplacement width of 25 $\mathrm{km}$. The central thinning is less pronounced, almost absent for the $\Delta \mathrm{h}=6 \mathrm{~km}$ case. This case will be called mode 3 or "Weakly thickening crust" and is defined by an axial thickness equal or only slightly thinner (within 20\%) than the far-field crust at $200 \mathrm{~km}$ distance.

It should be noted that the final crustal thickness of mode 1 to 3 cases outside the accretion zone are approximately identical (around $20 \mathrm{~km}$ as can be seen by Figures 4 and 6 for a half spreading rate of $1 \mathrm{~cm} / \mathrm{yr}$ ). For a given plume strength and spreading rate they are, to first order, independent of $\Delta \mathrm{h}$ and $\mathrm{d}_{\mathrm{acc}}$ as the feedback between crustal accretion and the melt extraction is small for crustal thicknesses below $20 \mathrm{~km}$ (see SM).

\section{Mode 4: Stagnating central block}

An interesting, but perhaps not very realistic mode of a stagnating central block has been found (Fig. 7). If the (half) emplacement width is $25 \mathrm{~km}$ (as in the previous model) and $\Delta \mathrm{h}$ is small (between 0 and $2 \mathrm{~km}$ ) then the accreting crustal material is too cold and stiff to allow for distributed stretching and crustal deformation. The central rift zone gets clogged by the stiff crust. As crust accretion continues to take place within the central emplacement zone of width $d_{a c c}$, stiff crustal material is continuously fed into this clogged rift zone with a rate that prohibits its escape sideways, and a thick, continuously subsiding block forms directly above the plume. The active rift zone is shifted to the side of the block. At this stage the model obviously becomes unrealistic because the locations of volcanic emplacement of the extracted melts and of the active rifting zone do not coincide anymore. To further explore this mode, 
more consistent coupling between the accretion and rifting process is needed. However, no statisfactory theory exists so far about how this coupling could be accomplished in nature or in numerical models.

\section{Regimes}

Varying the emplacement width and accretion layer thickness allows to identify the regimes of the three different modes (Fig. 8). For a half spreading rate of $1 \mathrm{~cm} / \mathrm{yr}$ (Fig. 8 top) the cold end member models with $\Delta \mathrm{h}=0$ either lead to extreme thick and stagnating crustal blocks (mode 4) if the emplacement width is smaller than a critical value of around $30-40 \mathrm{~km}$, or to a zero-thickness (necking) crust at the rift axis (mode 1) for larger emplacement widths. Increasing the accretion temperature, which is equivalent to increasing the accretion layer thickness $\Delta \mathrm{h}$ to $2 \mathrm{~km}$ or more, results in mode 2 or 3 -models with a crust of moderate thickness at the axis, thickening towards the sides. These lateral thickness variations are stronger for the models with larger emplacement widths (mode 2), while for smaller emplacement width almost constant thickness crust is generated (mode 3). Two models (with overlapping mode 3 and 4 symbols) started with a mode 3 - crust during a significant period of time, but, at a later stage, stagnated and switched to mode 4 .

Increasing the spreading rate (Fig. 8 middle and lower panel) suppresses the occurrence of stagnating blocks (mode 4). Instead, strong or weakly sideways thickening crust models were found for $2 \mathrm{~cm} / \mathrm{yr}$ (Fig. 8 middle). Increasing the half spreading rate to $4 \mathrm{~cm} / \mathrm{yr}$ (Fig. 8 bottom) produced zero thickness crust model the axis (mode 1) even for an emplacement width of $25 \mathrm{~km}$. Altogether, the trend of mode 3 models (almost constant crustal thickness) for smaller emplacements widths and mode 1 or 2 models (necking crust or sideways thickening crust) for large emplacement widths is maintained for the different spreading rates investigated. However, no unique trend is visible at intermediate emplacement widths: different spreading rates produce all different modes even for equal accretion layer thicknesses (c.f. columns for $25 \mathrm{~km}$ emplacement width with different spreading rates). For wider emplacement widths it can be stated that transition of mode 1 to mode 2 / 3 with increasing accretion layer thickness, i.e. increasing crustal weakening, is, on first order, independent of spreading rate. More hot and weak material is emplaced at higher spreading rates, but it is also transported away faster. 


\section{Far field crustal thicknesses}

While the above distinction between the different regimes applies for the axial region up to two times the emplacement width, the far field crustal thickness is essentially dependent on the spreading rate (and plume flux), but not on accretion layer thickness nor emplacement width. While the far field crustal thickness is about $21.3 \mathrm{~km}$ for the $1 \mathrm{~cm} / \mathrm{yr}$ half spreading model, this value drops to 16.2 or $12.6 \mathrm{~km}$ for 2 or $4 \mathrm{~cm} / \mathrm{yr}$, respectively. This drop is easily explained by the increasing role crust production due to spreading relative to crust production due to the plume (whose flux has been kept constant in the above models).

\section{Topography}

In this section only mode 1 to 3 spreading models will be considered. It is interesting to study the dynamic topography of the above models, and to see whether mode 2 or 3 models with some central thinning are still associated with central high topography as e.g. observed in Iceland. Although the vertical velocity of the model is zero at the top due to practical reasons, the surface topography $h_{\text {top }}$ can be determined from the vertical normal stress $\sigma_{z z}$ at the surface by equating $\sigma_{\mathrm{zz}}$ with $-\rho \mathrm{g} \mathrm{h}_{\text {top }}$ where $\rho$ is the density and $\mathrm{g}$ is the gravitational acceleration. It should be noted, that this topography includes both dynamic and isostatic contributions associated with any temperature-, melt- or depletion-induced density variation or flow due to the plume or normal mantle, and assumes instantaneous adjustment to the vertical normal stress. However, no effects due to elasticity, erosion or sedimentation are included. As the stress contains an arbitrary constant of integration, the topography is adjusted to values corresponding an average topography of $0 \mathrm{~km}$ over the whole model width.

Fig. 9) shows two snapshots at late stages of the models with $50 \mathrm{~km}$ and $25 \mathrm{~km}$ wide emplacement widths and a half spreading rate of $1 \mathrm{~cm} / \mathrm{yr}$.. Clearly the mode 1 cases (Fig. 9a, blue and green curves, $\Delta \mathrm{h}=0$ and $2 \mathrm{~km}$ ) show a deep rift graben with a local and narrow relative maximum at the rift axis. Large undulations occur between 0 and $120 \mathrm{~km}$, i.e. within the range of magma emplacement (c.f. Figs. 2 and 4). As the behaviour switches to mode 2 (moderate central crustal thickness thickening sideways) the central graben almost disappears, but a large scale depression of several $100 \mathrm{~m}$ remains. Given the densities of the crust and mantle, and the taking the crustal thicknesses as resulting from the models (Fig. 4) isostatic depressions of $2.5-3 \mathrm{~km}$ would be expected instead. Thus, the dynamic contribution to topography is at least 1.5 to $2 \mathrm{~km}$ for the mode 2 cases of Fig. 9a). 
For a narrower emplacement zone $(25 \mathrm{~km})$ the topographies of mode 2 models are shown in Fig. 9b). Although these models still show slightly thinned crust at the axis (c.f. Fig. 6), which would be associated with an isostatic topographic depression of 0.5 or $1.2 \mathrm{~km}$, respectively, the full topography has an absolute maximum within a $50 \mathrm{~km}$ range of the rift axis. Only within the immediate vicinity ( $5 \mathrm{~km}$ ) of the axis a deep dynamically induced graben has developed, however, the exact depth may be beyond the resolution of the model.

\section{Discussion}

No mode with maximum thickness at rift axis

It is interesting to note that within the parameter range investigated no further mode with a spreading crust which is thickest at the axis has been found (as the stagnating block models are not considered as realistic). This is in contrast to studies like Jones and MacLennan (2005) who assumed a central maximum crust thickness as initial condition of their crust flow model motivated by observations (Darbyshire et al., 2000). In their dynamical crust formation models Ruedas et al. (2004) obtained a maximum crustal thickness near the rift axis. Based on the present results a thinner crust in the central region may be due to the dynamics and rheological feedback of the crustal accretion process, which has been neglected in the two studies mentioned above. A thinner crust within the central region is in agreement with the results by Bjarnsaon and Schmeling (2009) based on seismic surface waves, but in contrast to earlier crustal models with highest thickness in Central Iceland (Darbyshire et al. 2000) (c.f. Fig. 1).

Given these conflicting results it is important to discuss how robust is the result of a missing fifth mode with a thickest crust near the axis. It cannot be excluded that such a fifth mode exists for other combinations of rheological or dynamical parameters. For example, in this study no dehydration stiffening effect has been accounted for (Ito et al., 1999). As has been shown by Ruedas (2006) melt production and crust generation is strongly affected by dehydration of the plume upon melting and the associated increase of the plume head viscosity: the crust production rate is reduced significantly, but whether also the lateral thickness variations are affected could not be resolved by the models of Ruedas (2006). A possible increase of the sub-crustal viscosity in dynamic models such as those presented here might affect both the crustal stretching zone and the accretion zone. Therefore it is difficult to predict which of these two zones will broaden more if the effect of dehydration stiffening would be accounted for. Because the ratio of widths of these two zones is essential in 
controlling thinning or thickening of the crust (Ruedas and Schmeling, 2008) lateral variations of the crustal thickness cannot be estimated before carrying out such models.

Is mode 1 (zero crustal thickness at axis)) found in nature?

Oceanic crustal thicknesses of normal and anomalous oceanic crusts and half spreading rates of $1 \mathrm{~cm} / \mathrm{yr}$ or more never seem to show a lateral decrease to zero thickness near the rift axis (c.f. the compilation shown in Ruedas and Schmeling, 2008). Thus it may be concluded that the cold accretion mode equivalent to shallow crustal accretion within a thin accretion layer of thickness $\Delta \mathrm{h}(<4 \mathrm{~km})$ (mode 1$)$ is not realized on earth for small spreading rates. As indicated by Fig. 8) at higher spreading rates this critical value might be somewhat lower ( $\Delta \mathrm{h}<2 \mathrm{~km})$, This is in agreement with the results of Schmeling and Marquart (2008) who showed that an intermediate to deep accretion mode is the most preferred mode for Iceland.

\section{Effect of other parameters}

Tests with different crustal rheologies have been carried out (stronger than the clinopyroxenite -rheology used here, stronger or no Byerlee type plasticity). As expected, they show a correlation with the accretional heating (i.e. with $\Delta \mathrm{h}$ ). This means that if the crust would have a stronger (weaker) rheology than assumed here, the boundary below the mode 2 / 3 cases (Fig. 8) would shift to higher (lower) $\Delta \mathrm{h}$ - values.

The plume flux has been kept constant in the present models. The effect of varying plume flux can be inferred from the behaviour of two of the models, namely the models with $\Delta \mathrm{h}=2$ $\mathrm{km}, \mathrm{d}_{\mathrm{acc}}=12.5 \mathrm{~km}, 1 \mathrm{~cm} / \mathrm{yr}$, and $\Delta \mathrm{h}=0 \mathrm{~km}, \mathrm{~d}_{\mathrm{acc}}=25 \mathrm{~km}, 2 \mathrm{~cm} / \mathrm{yr}$ (c.f. Fig. 8 top and middle), respectively. These models show mode 3 evolution during the first stage of enhanced melt generation (and crust accretion). As the melt generation rate decreases a bit during the model evolution, the models eventually switched to mode 4 (stagnating central block). Thus it can be inferred that increasing (decreasing) the plume flux (and accordingly the crust generation rate) would shift the boundary below the mode 3 cases (and probably also mode 2 cases) (Fig. 8) to lower (higher) $\Delta \mathrm{h}$ - values.

What controls the layer thickness and the emplacement width?

In this study the accretion layer thickness and emplacement width have been used as the independent variables to model crustal accretion. Which quantities or processes control these 
variables? Obviously, the accretion layer thickness is controlled by the dynamics of the accretion process itself, probably most importantly by the interaction between temperature, hydrothermal cooling, rheology, and extension rate, leading to extensional stress conditions allowing or not allowing the melts to reach close to the surface. These dynamic stress conditions are responsible for melts to ascend to significantly shallower depths than their depth of neutral buoyancy (Gerya and Burg, 2007).

The other variable, the emplacement width, is controlled by the mechanisms of melt ascent from the mantle source region to the emplacement zone, i.e. by focussing of melt towards the ridge or rift axis. A number of physical mechanisms have been proposed for melt focussing (see e.g. the review by Kelemen et al., 1997) in order to explain the difference in width of the mantle melting zone (order of $100 \mathrm{~km}$ ) and the width of a spreading ridge (order of less than 10 km). Melt ascent by propagating dykes (e.g. Phipps Morgan, 1987; Kühn and Dahm, 2004) predict rather weak focussing, i.e. would result in wide emplacement widths (40km on either side). Similarly weak focussing is found for porous flow with isotropic permeability (e.g. Phipps Morgan, 1987; Ribe, 1988), unless the asthenosphere viscosity is as high as $10^{20} \mathrm{~Pa}$ s. Melt focussing (i.e. small emplacement widths) might occur by subhorizontal melt flow towards the ridge within a high permeability layer which may form directly beneath the cooling and freezing front of a spreading lithosphere (Sparks and Parmentier, 1991; Ghods and Arkani-Hamed, 2000). In the deviatoric stress field of a non-Newtonian mantle beneath a spreading ridge melt shear bands may form which are inclined towards the ridge axis, and thus have the potential to strongly focus the melt (Katz et al., 2006). While the above mentioned studies are related to mid-ocean ridges, the effect of a hot ridge centred plume on the focussing effect has not yet been studied as extensively. Geologic evidence shows that the width of the neo-volcanic zone in Iceland above the presumed plume has an emplacement width of approximately 50 - $75 \mathrm{~km}$, i.e. much wider compared to normal mid-ocean ridges. Ruedas and Schmeling (2008) showed that a ridge centred plume adds a stress field in a way as to further reduce the weak focussing effect of ascending dykes.

This discussion shows that a wide variety of mechanisms may produce quite different emplacement widths, and that anomalously hot ridges may be associated with wider emplacement zones. 
While the above models have been designed as to match the Iceland case and resolve the conflicting observations about crustal thickness variations there, they may in general also be applied to other plume-ridge settings. However, it should be noted that a strict application requires a ridge centred plume with a constant plume buoyancy flux. Off-axis plumes will produce more complex crustal thickness variations due to their time-dependent distance from the axis, especially for fast spreading ridges. Such distance variations affect the magma supply to the ridge leading to crustal thickness variations difficult to separate from the variations obtained in the present paper.

Apart from Iceland the Azores hotspot might be an example of an almost ridge-centred plume (about $130 \mathrm{~km}$ off the mid-Atlantic ridge). Crustal thickness variations across the MidAtlantic ridge close this hotspot show a thickness of $8-6 \mathrm{~km}$ at the axis increasing to $14-7$ km off-axis, respectively, at an axial distance of about 65 - $110 \mathrm{~km}$ (Escartin et al., 2001). The strongest increase is observed for the ridge segments closest to the hotspot. Escartin et al. (2001) explain the observed crustal thickness variations by a time-dependent supply of magmatic material associated with a laterally propagating magma pulse along the ridge. However, applying the dynamic accretion model of the present paper the observed crustal structures might alternatively be interpreted by a transition from mode 2 (strongly thickening) to mode 3 (weakly thickening) crustal accretion with increasing distance from the plume centre. Such a transition would take place if the emplacement width decreases (c.f. Fig. 8), which is consistent with less plume material supply and cooler temperatures associated with stiffer rheology.

Another case of plume-ridge interaction is the Galapagos Hotspot. This hotspot is located approximately $200 \mathrm{~km}$ SSW of the spreading ridge between the Cocos and the Nasca plates, at a position where the half spreading rate is approximately $2.4 \mathrm{~cm} /$ year. Crustal thickness variations of that area have been inferred from gravity data by Feighner and Richards (1994) and indicate a crustal thickness maximum of $20 \mathrm{~km}$ at the Galapagos archipelo situated about $100 \mathrm{~km}$ away from the ridge. The crustal thickness deceases towards the ridge to about $10 \mathrm{~km}$. Applying the accretion model of this study suggests that thinning towards the ridge might correspond to a mode 2 accretion case, found for relatively wide emplacement widths and thick accretion thicknesses. However, care has to be taken because presently in the hotspot reference system the ridge migrates to the north with $2-3 \mathrm{~cm} /$ year (Gripp and Gordon, 2002), while the hotspot moves to the SWW with several cm/year (Steinberger, 2000). Thus, the hotpot - ridge offset increases with time which may result in a gradual decrease of feeding 
plume material into the ridge. This effect may lead to crustal thinning towards the ridge superimposed to the thickness variations predicted by the present accretion model.

\section{Conclusion}

Crustal accretion models have been carried out for a mid-ocean spreading system underlain by a hot upwelling plume. The spreading zone develops dynamically and rheologically consistently as a result of externally applied plate velocities. The crust forms as a result of extracted melt fed back into the system. The dynamics of spreading and crust formation are thermally and rheologically controlled by the feedback due to accreted new crust. The following conclusions can be drawn:

- Four accretional modes with characteristic crustal thickness variations have been identified depending on the width of the volcanic emplacement zone and the accretional heating rate, which can be associated with the thickness of the surface layer in which accretion due to volcanic emplacement takes place.

- $\quad$ Mode 1: Zero crustal thickness at the spreading axis develops for cool (shallow) accretion $(\Delta \mathrm{h}<4 \mathrm{~km})$ and wide emplacement zones.

- $\quad$ Mode 2: Strongly crustal thickening away from the axis develops in case of warm (deep reaching) accretion ( $\Delta \mathrm{h}>4 \mathrm{~km}$ ) and wide emplacement zones.

- $\quad$ Mode 3: Nearly constant crustal thickness develops in case of warm (deep reaching) accretion ( $\Delta \mathrm{h} \geq 4 \mathrm{~km}$ ) but narrow emplacement zones..

- $\quad$ Mode 4: Cool accretion and narrow emplacement leads to a stagnating central block. This mode disappears for increasing spreading rates.

- No accretional mode with maximum crustal thickness above the plume at the rift axis has been found.

- Mode 3 or 2 (nearly constant crustal thickness or moderately crustal thickening towards the sides) is in general agreement with the structure of the Icelandic crust as determined by Bjarnason and Schmeling (2009).

- Mode 3 or 2 may also be responsible for the crustal structure observed near the Azores and the Galapagos hotspots. 
- Mode 2 to 3 models with thinned crust near the axis show dynamic topography with only weak or no regional minimum at all near the axis. This may explain why the thinned crust in central Iceland is not associated with a depression as one would expect on the grounds of isostacy.

- Mode 1 accretion (with zero crust at ridge axis) is not found in natural spreading ridge zones with half spreading rates of $1 \mathrm{~cm} / \mathrm{yr}$ or larger implying that in general crustal accretion is not cold (and not shallow).

\section{Acknowledgment}

This work has been done during a sabbatical leave at the University of Honolulu, Hawaii, USA. I enjoyed the fruitful discussions with G. Ito, E. Mittelstedt and T. Bianco. This work has been supported by Deutsche Forschungsgemeinschaft (grant Schm872/21-1)

\section{References}

Bai, Q., S. J. Mackwell, and D. L. Kohlstedt, 1991: High temperature creep of olivine single crystals: Mechanical results for buffered samples. J. Geophys. Res., 96, 2441 - 2463.

Bjarnason, I. T. and H. Schmeling, 2009: The structure of the lithosphere and asthenosphere of Iceland from surface waves. Geophys. J. Int. , 178, 394 - 418.. doi: 10.1111/j.1365246X.2009.04155.X

Darbyshire, F. A:, R. S. White and K. F. Priestley, 2000: Structure of the crust and uppermost mantle of Iceland from a combined seusmic and gravity study. Earth Planet. Sci. Lett., $181,409-428$.

Escartin, J., M. Cannat, G. Pouliquen, A. Rabain, 2001 : Crustal thickness of V-shaped ridges south of the Azores : Interaction of the Mid-Atlantic Ridge $\left(36^{\circ}-39^{\circ} \mathrm{N}\right)$ and the Azores hot spot. J. Geophys. Res., 106, $21719-21732$

Fedorova, T., W. R. Jacoby, H. Wallner, 2005: Crust-Mantle Transition and Moho Model for Iceland and Surroundings from Seismic, Topography and Gravity Data, Tectonophysics, 396 (3-4): 119-140 .

Feighner, M. A., and M. A. Richards, 1994: Lithospheric structure and compensation mechanisms of the Galápagos Archipelago, J. Geophys. Res., 99(B4), 6711-6729.

Gerya, T.V. and J.-P. Burg, 2007: Intrusion of ultramafic bodies into the continental crust: Numerical simulation. Phys. Earth Planet. Int., 160, $124-142$.

Ghods, A. and J. Arkani-Hamed, 2000: Melt migration beaneath mid-ocean ridges. Geophys. J. Int., 140, 687 - 697

Gripp, A.E., and Gordon, R.G., 2002: Young tracks of hotspots and current plate velocities, Geophys. J. Int., 150, 321-361.

Ito, G., J. Lin and D. Graham, 2003: Observational and theoretical studies of the dynamics of mantle plume-mid-ocean ridge interaction. Rev. Geophys., 41(4), 1017, 3-1-3-24.

Ito, G., Y. Shen, G. Hirth, and C. J. Wolfe, 1999: Mantle flow, melting and dehydration of the Iceland mantle plume. Earth Planet.Sci.Lett., 165:81-96. 
Jones, S. M., and J. Maclennan, 2005: Crustal flow beneath Iceland, J. Geophys. Res., 110, B09410,doi:10.1029/2004JB003592

Kaban MK, Flovenz OG, Palmason G , 2002: Nature of the crust-mantle transition zone and the thermal state of the upper mantle beneath Iceland from gravity modelling GEOPHYSICAL JOURNAL INTERNATIONAL 149 (2): 281-299

Kelemen, P. B., G. Hirth, N. Shimizu, M. Spiegelman and H. J. B. Dick, 1997: A review of melt migration processes in the adiabatically upwelling mantle beneath oceanic spreading ridges. Phil. Trans. R. Soc. Lond. A, 355, 283 - 318.

Katz, R. F., M. Spiegelman and B. Holtzman, 2006: The dynamics of melt and shear localization in partially molten aggregates, Nature, 10.1038/nature05039 p676.

Kirby, S. H. and A. K. Kronenberg, 1987: Correction to "Rheology of the lithosphere: Selected topics”. Rev. Geophys. 25, No 8, 1680 - 1681.

Kühn, D. and T. Dahm, 2004: Simulation of magma ascent by dykes in the mantle beneath mid-ocean ridges. J. Geodyn., 38(2), 147 - 159.

McKenzie, D., 1984: The generation and compaction of partially molten rock. J. Petr., 25, 713-765.

Menke, W., 1999: Crustal Isostasy Indicates Anomalous Densities Beneath Iceland, Geophys. Res. Lett., 26(9), 1215-1218.

Phipps Morgan, J., 1987: Melt migration beneath mid-ocean spreading centers. Geophys. Res. Lett., 14, 1238-1241.

Ribe, N. M., 1988: On the dynamics of mid-ocean ridges. J. Geophys. Res., 93, 429 - 436.

Ruedas, T. and H. Schmeling, 2008: Kinematic models for the thickness of oceanic crust at and near mid-oceanic spreading centers. J. Geophys. Res., 113, B01402, doi:10.1029/2006JB004746.

Ruedas, T., H. Schmeling, G. Marquart, A. Kreutzmann, A. Junge, 2004: Dynamics and melting of a ridge-centered plume with application to Iceland, part I: Evolution and crust production. Geophys. J. Int., 158(2), 729-743.743

Ruedas, T., 2006: Dynamics, crustal thicknesses, seismic anomalies, and electrical conductivities in dry and hydrous ridge-centered plumes; in press, Phys. Earth Planet. Int., Volume 155, 16 - 41.

Ruedas, T., H. Schmeling, 2008: On the orientation of tensile dikes in a ridge-centered plume. Tectonophysics. 447, 19 - 30. doi:10.1016/j.tecto.2006.01.030

Schmeling, H., 2006: A model of episodic melt extraction for plumes, J. Geophys. Res., 111, B03202, doi:10.1029/2004JB003423

Schmeling, H., 2000: Partial melting and melt segregation in a convecting mantle. In: Physics and Chemistry of Partially Molten Rocks, eds. N. Bagdassarov, D. Laporte, and A.B. Thompson, Kluwer Academic Publ., Dordrecht, pp. 141 - 178.

Schmeling, H. and G. Y. Bussod, 1996: Variable viscosity convection and partial melting in the continental asthenosphere. J. Geophys. Res., 101, 5411 - 5423.

Schmeling, H. and G. Marquart, 2008 : Crustal accretion and dynamic feedback on mantle melting of a ridge centred plume: the Iceland case. Tectonophysics. 447, 31 - 52. doi:10.1016/j.tecto.2006.08.012.

Sparks, D. W and E. M. Parmentier, 1991: Melt extraction from the mantle beneath spreading centers. Earth Planet. Sci. Lett., 105, 368 - 377.

Steinberger, B., 2000: Plumes in a convecting mantle: Models and observations for individual hotspots. J. Geophys. Res., 105, $11127-11152$

White, R.S., 1993: Melt production rates in mantle plumes. Phil. Trans. R. Soc. Lond. A, 342, $137-153$ 


\section{Figures}

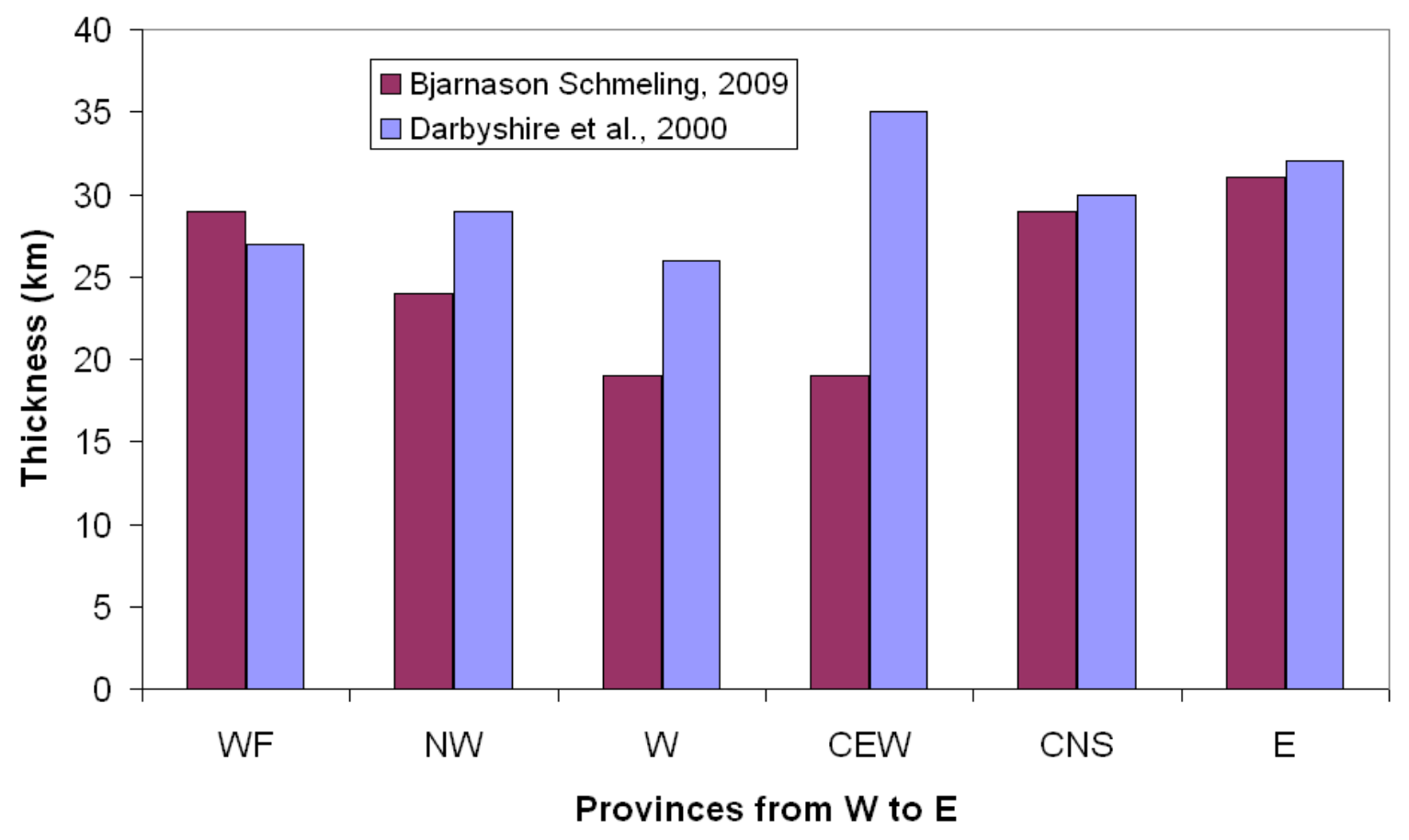

Fig. 1. Crustal thicknesses of Iceland from different studies plotted for different provinces of Iceland. WF: West Fjords, NW: Northwest Iceland, W: West Iceland and the West Volcanic Zone, CEW: Central Iceland profile with E-W azimuth, CNS: Central Iceland profile with $\mathrm{N}-\mathrm{S}$ azimuths (Neovolcanic rift zone); E: East Iceland. (see Bjarnason and Schmeling, 2009, for the location of the profiles). The values of Darbyshire et al. (2000) have been roughly estimated visually from their map, averaging the crustal thickness along the indicated profiles. 


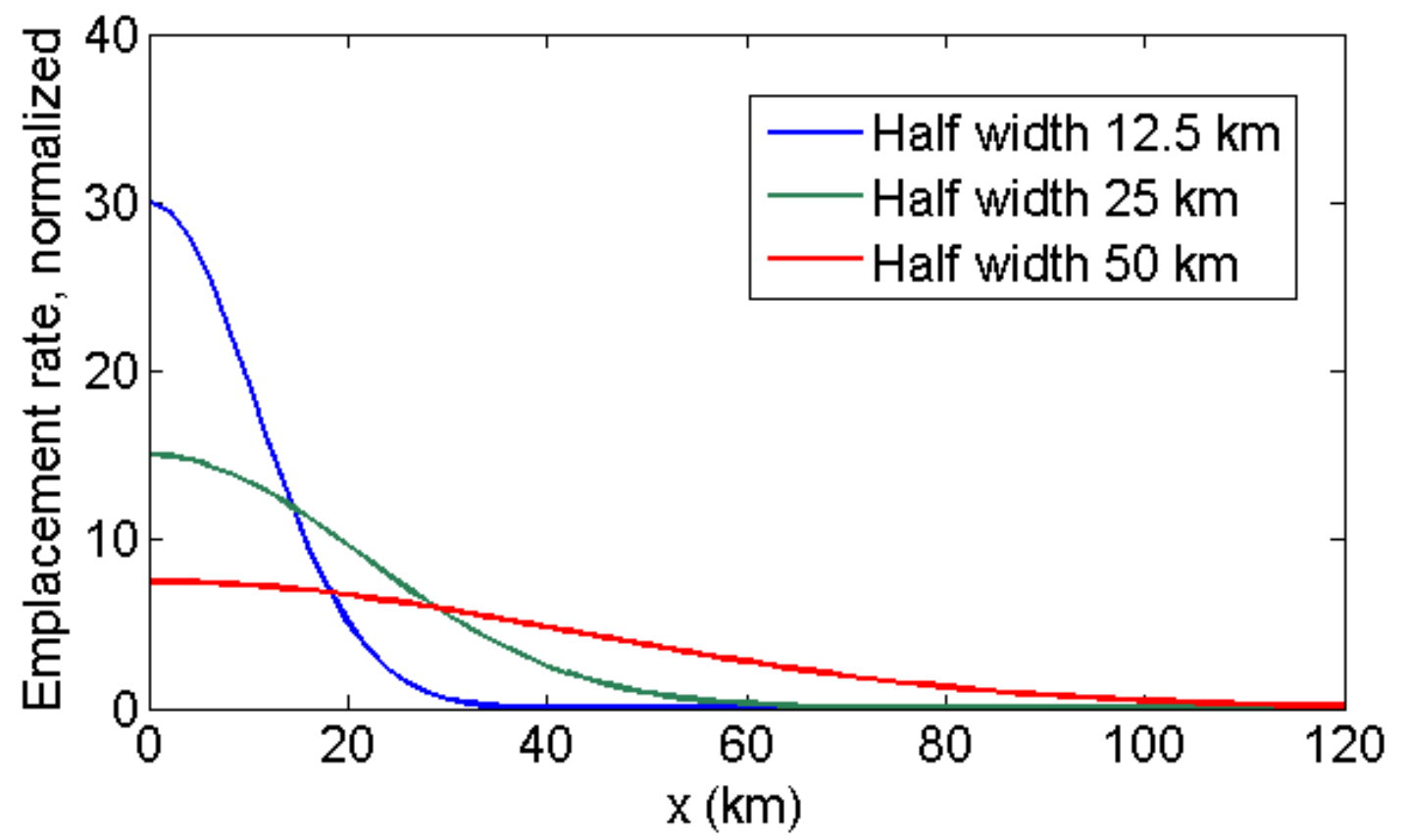

Fig. 2: Normalized emplacement rate functions G(x) used to feed back the extracted magma into the model at the surface for different values of $d_{a c c}$, 

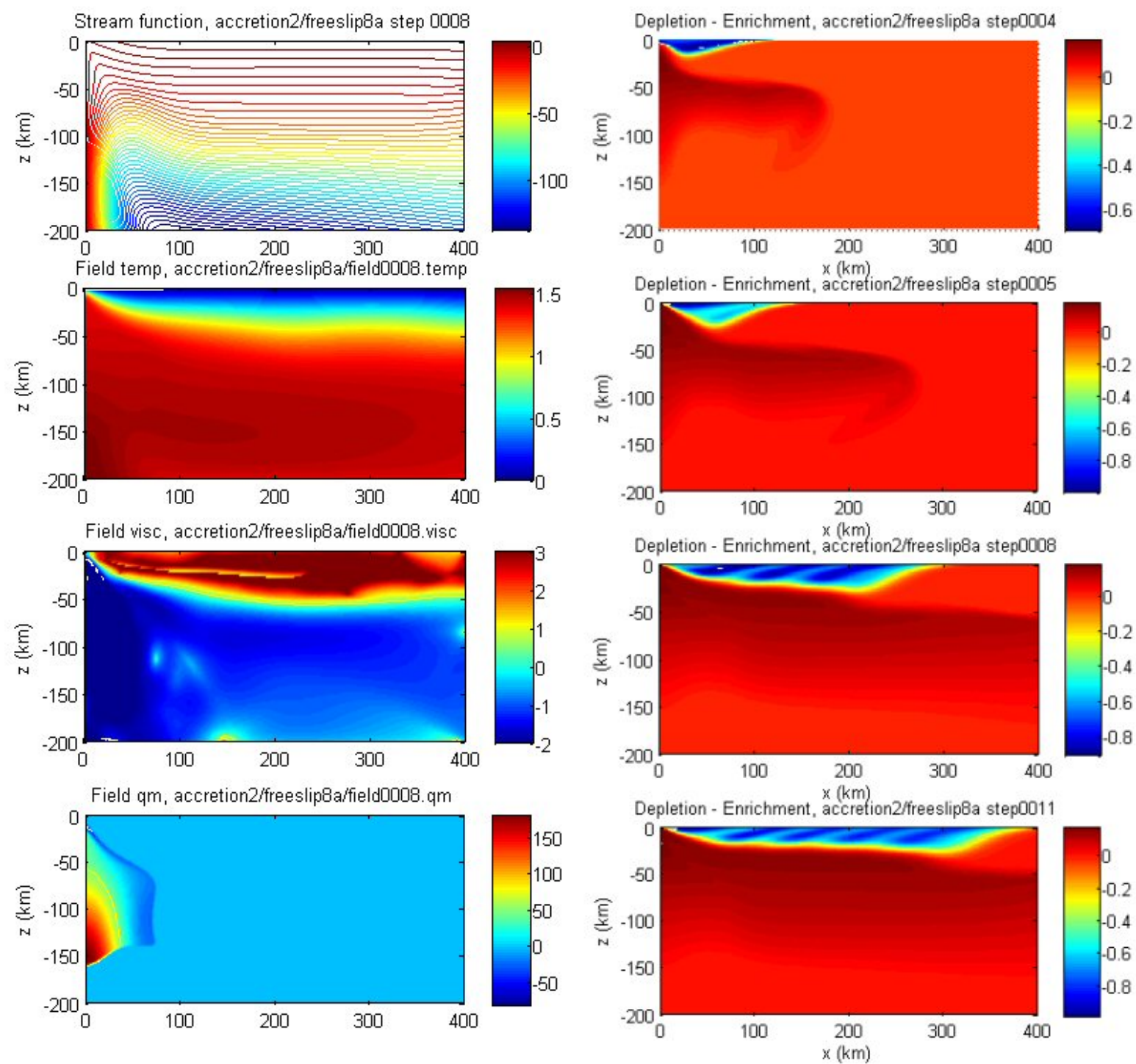

Figure 3. Model with emplacement width $50 \mathrm{~km}$ and cold accretion $(\Delta \mathrm{h}=0 \mathrm{~km})$ and a half spreading velocity of $1 \mathrm{~cm} / \mathrm{yr}$. Mode 1 crust formation: asthenospheric wedge reaches almost to the surface, crustal thickness is $0 \mathrm{~km}$ at the rift axis. Left column top to bottom:

Streamlines, Temperature (scaled by $1000 \mathrm{~K}$ ), $\log _{10}$ viscosity (viscosity scaled by $10^{21} \mathrm{~Pa}$ ), and volumetric melt generation rate scaled by $2.5 \cdot 10^{-17} \mathrm{~s}^{-1}$ (negative values mean freezing). All left figures at time 17.7 Myr after onset of rifting. Right column: Evolution of the depletion field (red part of figures, maximum at 0.16 i.e. $16 \%$ depletion) and accreted crust (blue regions) at times (from top to bottom): 0, $5 \mathrm{Myr}, 17 \mathrm{Myr}$ and $25 \mathrm{Myr}$. The dark - light blue color variations within the crust highlight the accretion process and are artificially produced by periodically varying the depletion-value of the accreting material between -1 and $-0 . .5$, but keeping the physical properties independent of these variations. 


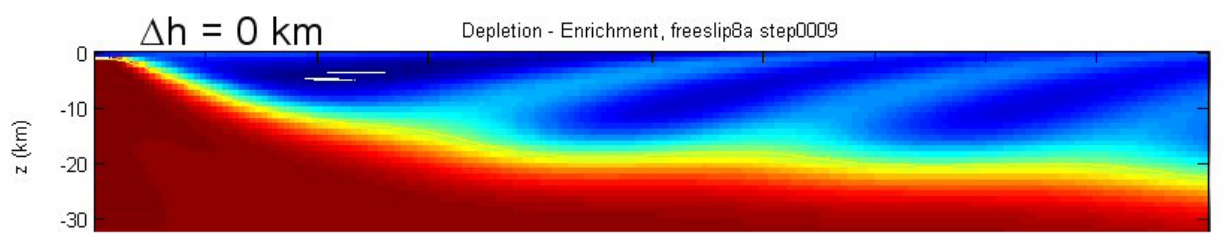

$\Delta \mathrm{h}=2 \mathrm{~km}$
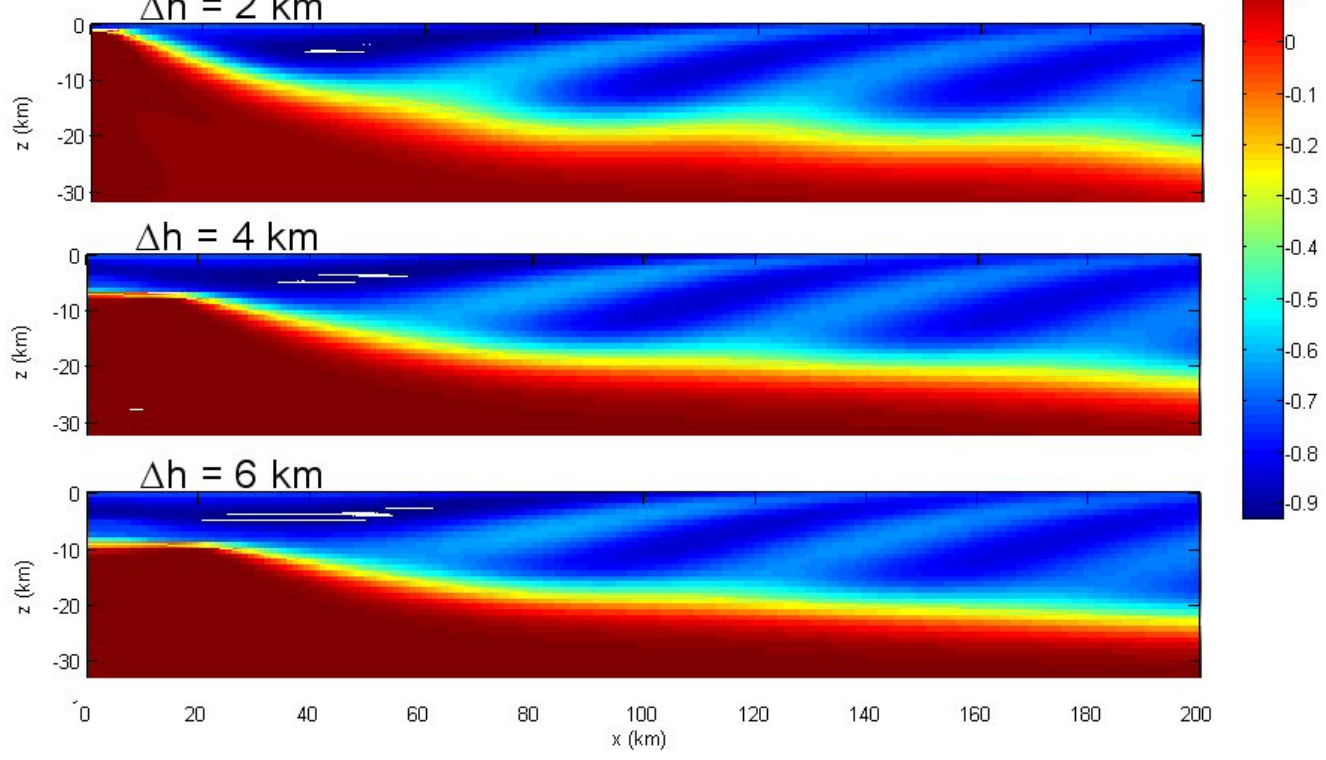

Fig. 4: Crustal thickness and structure of a model with $50 \mathrm{~km}$ wide (half-) emplacement zone and different accretion thicknesses $\Delta \mathrm{h}$ at a late stage (25 Myr). The half spreading rate is 1 $\mathrm{cm} / \mathrm{yr}$. With increasing $\Delta \mathrm{h}$ the crustal influx temperature within the emplacement zone increases weakening the crust and lithosphere near the axis and widening the stretching zone. The colors give the depletion and are artificially modified as explained in the caption of Fig. 3. 


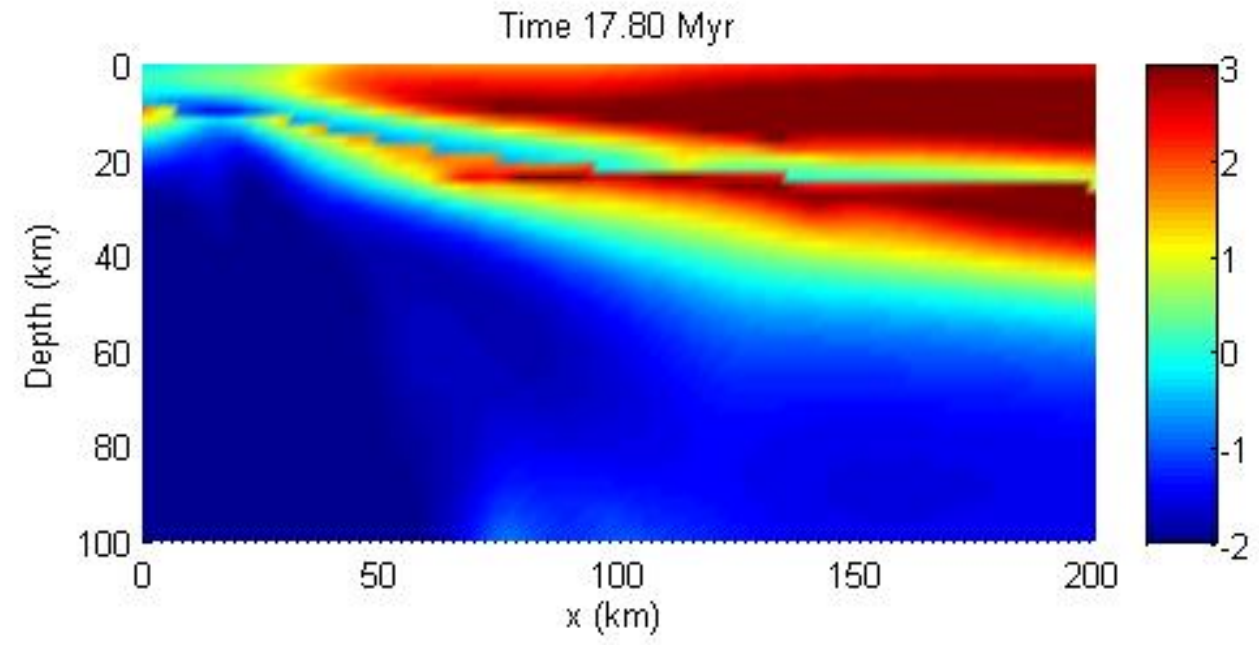

Fig. 5. Close up of the $\log _{10^{-}}$viscosity field near the ridge of the mode of Fig. 2 , but for $\Delta \mathrm{h}=$ $6 \mathrm{~km}$. The viscosity is scaled by $10^{21} \mathrm{~Pa}$. 


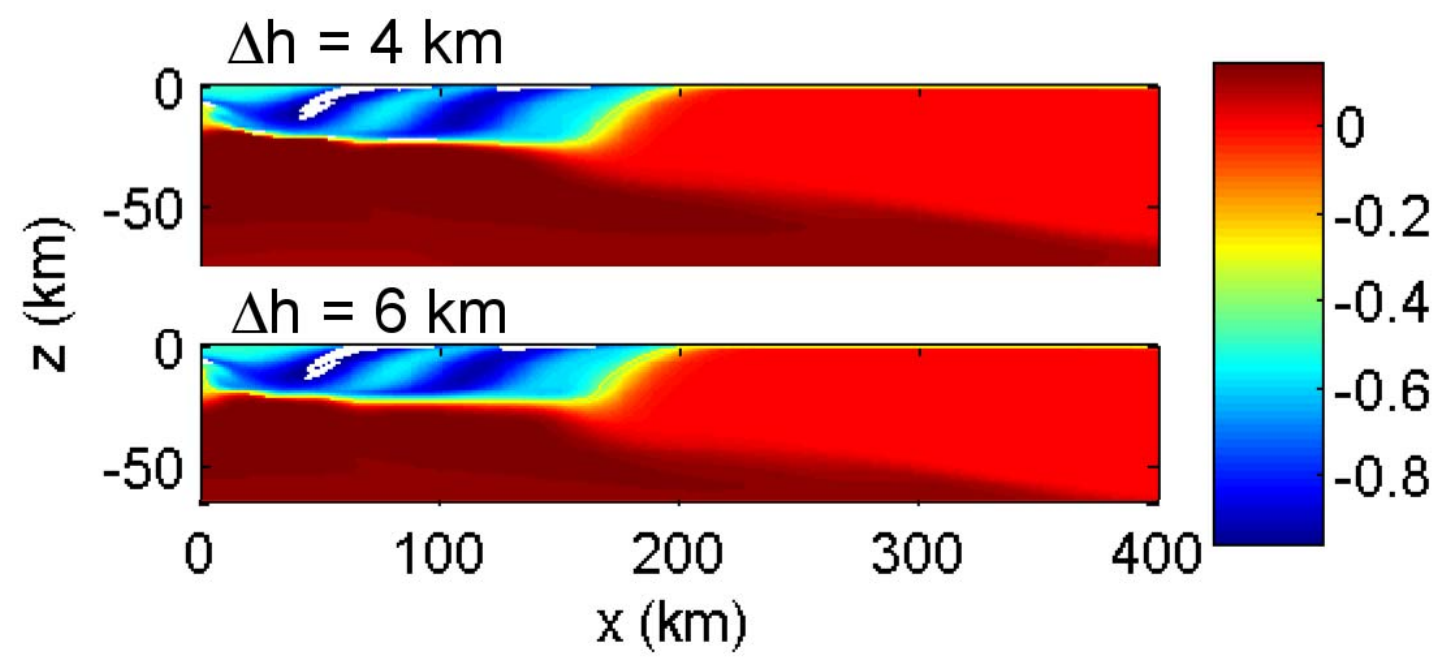

Fig. 6. Same as Fig 3, but (half) emplacement width reduced to $25 \mathrm{~km}$. Time: $12 \mathrm{Myr}$. The colors give the depletion and are artificially modified as explained in the caption of Fig. 3. 


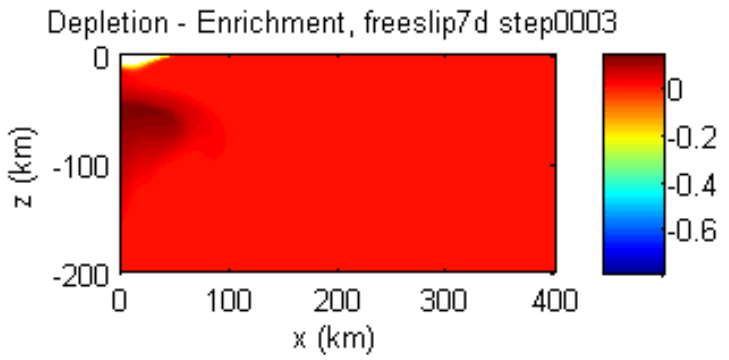

Depletion - Enrichment, freeslip7d step0004

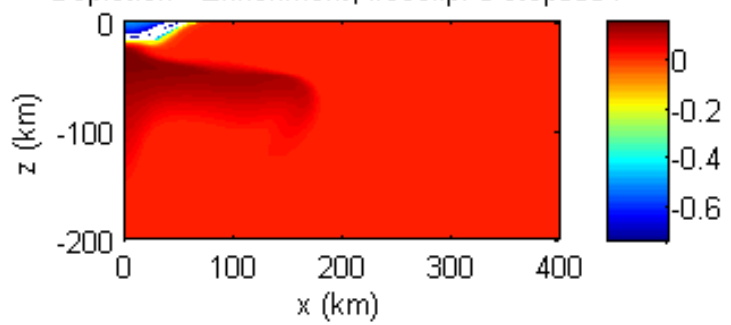

Depletion - Enrichment, freeslip7d step0005

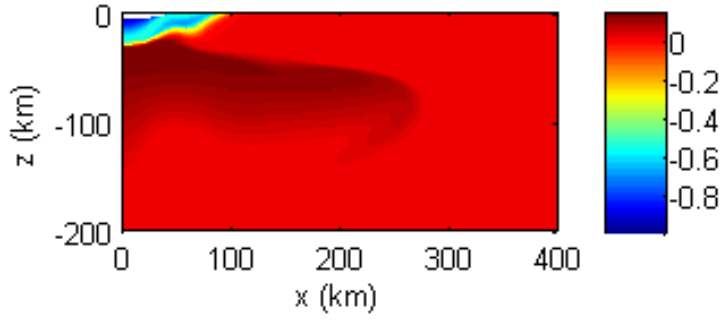

Depletion - Enrichment, freeslip7d step0006

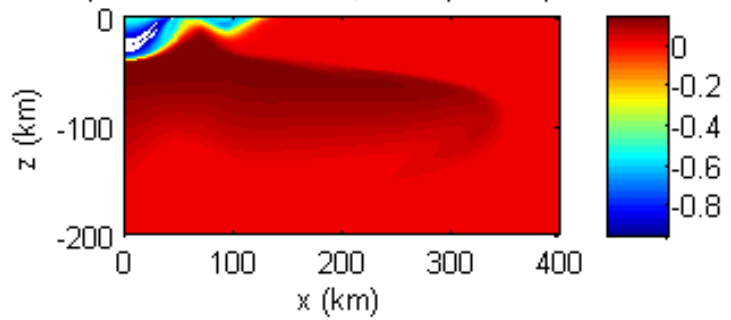

Depletion - Enrichment, freeslip7d step0008

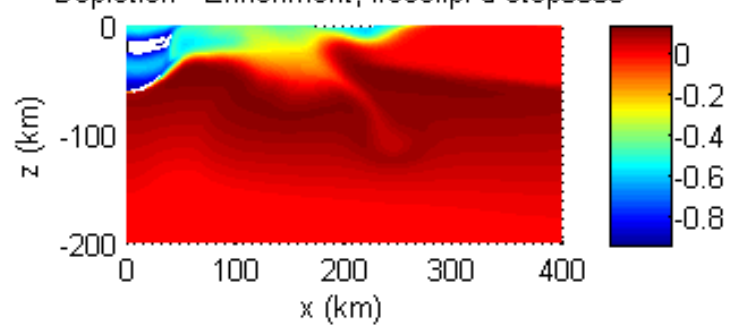

Fig 7. Example of mode 4 model, where the accreting crust is stiff and forms a stagnating block. The colors give the depletion and are artificially modified as explained in the caption of Fig. 3.. 

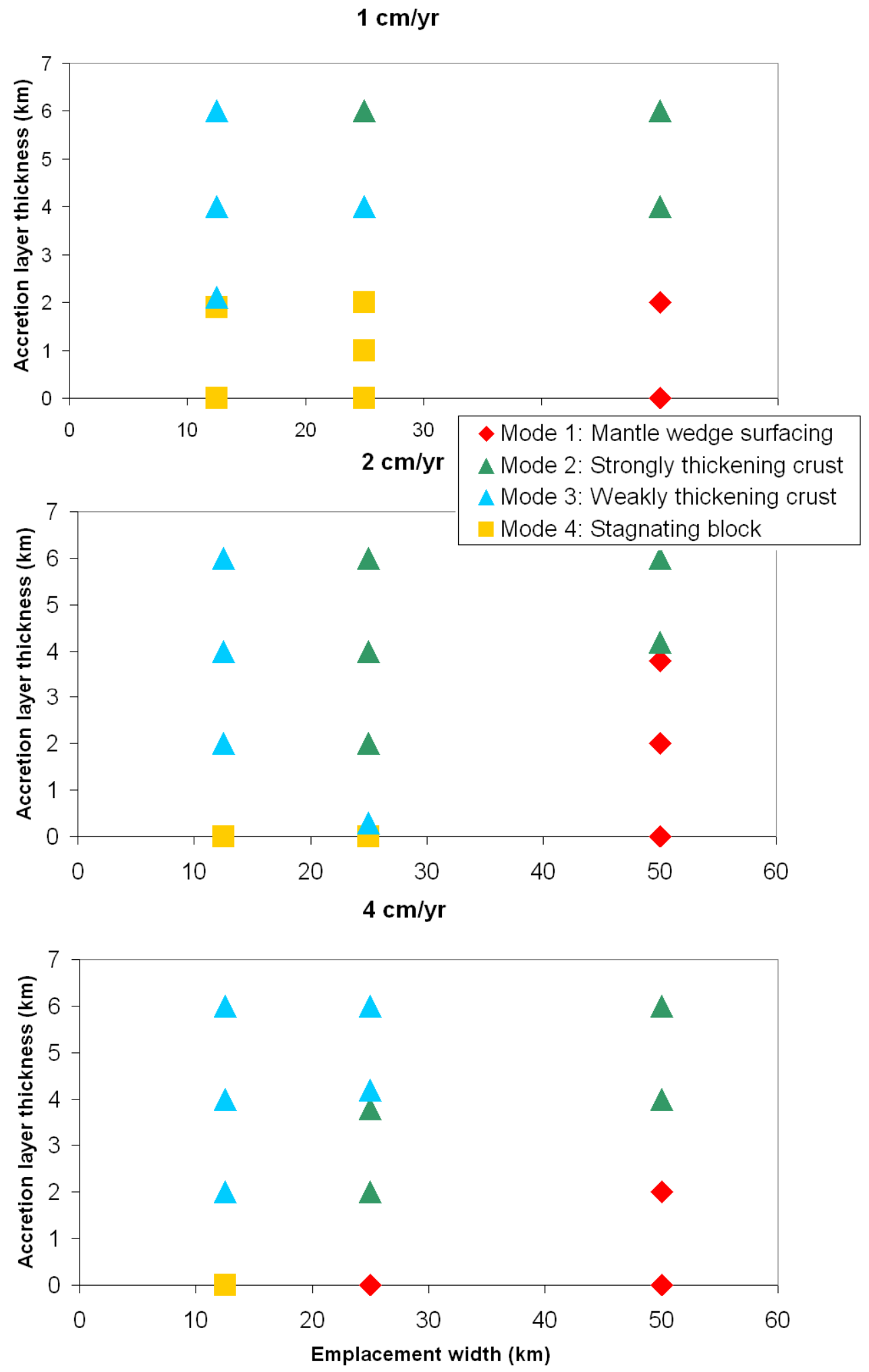

Fig. 8. Regimes of the four modes of crust formation for different (half-) spreading velocities increasing from top to bottom. 
a)

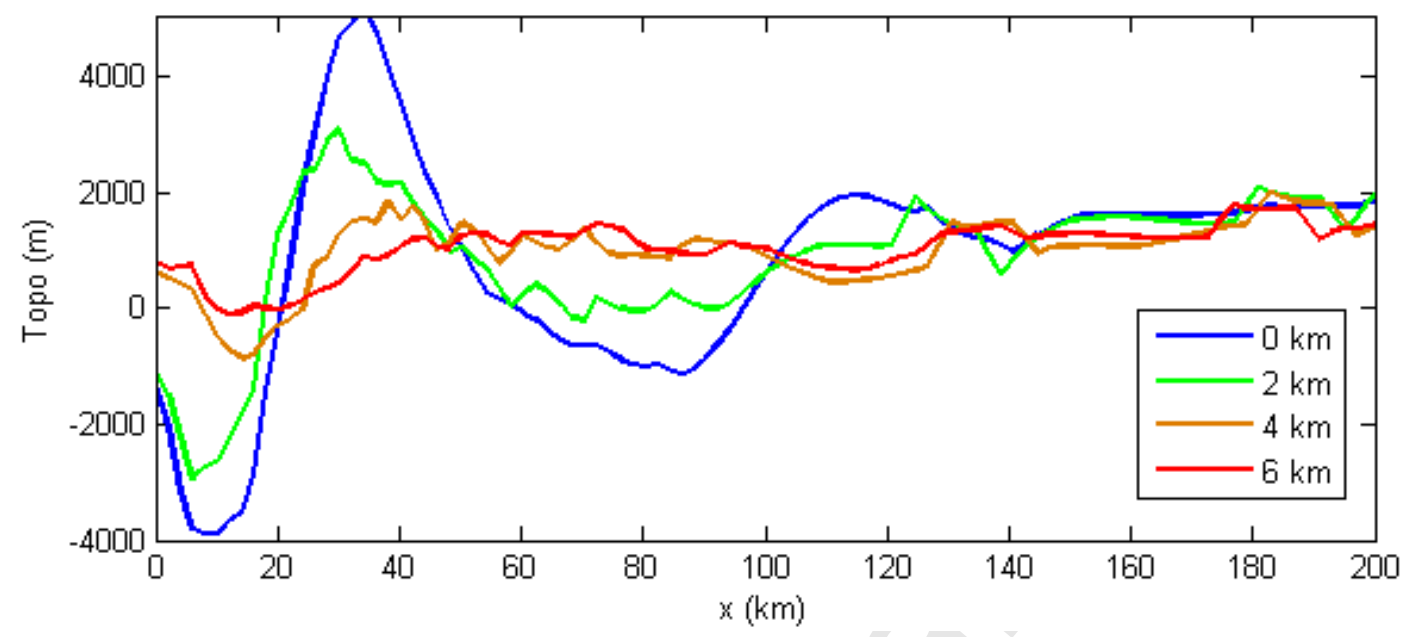

b)

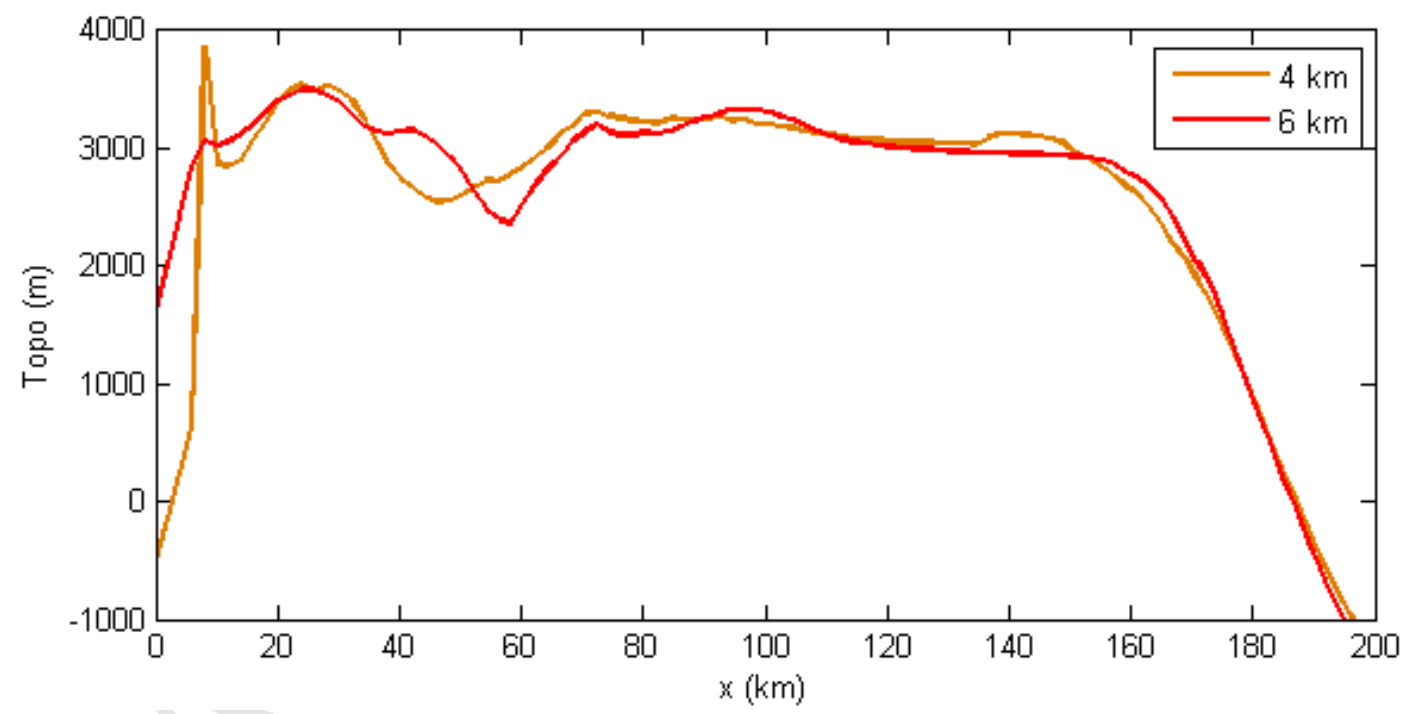

Figure 9. Dynamic topography of models with half spreading rate $1 \mathrm{~cm} / \mathrm{yr}$ and different emplacement widths. a) (half) emplacement width $50 \mathrm{~km}$ (models shown in Figure 3) at the time 21 Myr. The numbers in the legend give the equivalent accretion layer thicknesses. b) (half) emplacement width $d_{\mathrm{acc}}=25 \mathrm{~km}$ (c.f. Fig. 5) after 12 Myr. At distances larger than 160 $\mathrm{km}$ the shelf is still visible. 